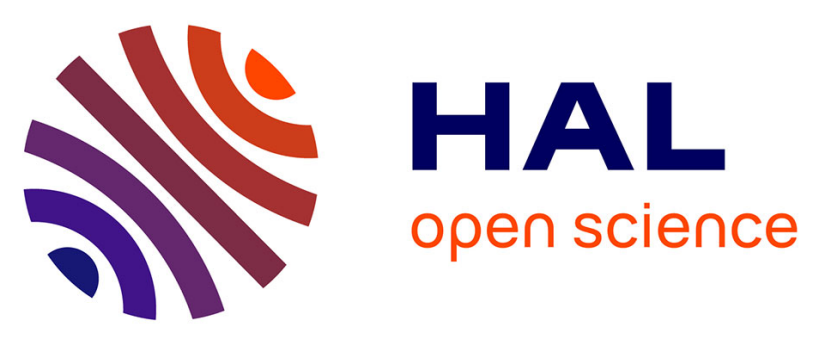

\title{
Evaluating order acceptance policies for divergent production systems with co-production
}

Ludwig Dumetz, Jonathan Gaudreault, André Thomas, Nadia Lehoux, Philippe Marier, Hind El-Haouzi

\section{- To cite this version:}

Ludwig Dumetz, Jonathan Gaudreault, André Thomas, Nadia Lehoux, Philippe Marier, et al.. Evaluating order acceptance policies for divergent production systems with co-production. International Journal of Production Research, 2017, 55 (13), pp.3631-3643. 10.1080/00207543.2016.1193250 . hal01319726

\section{HAL Id: hal-01319726 \\ https://hal.science/hal-01319726}

Submitted on 23 May 2016

HAL is a multi-disciplinary open access archive for the deposit and dissemination of scientific research documents, whether they are published or not. The documents may come from teaching and research institutions in France or abroad, or from public or private research centers.
L'archive ouverte pluridisciplinaire HAL, est destinée au dépôt et à la diffusion de documents scientifiques de niveau recherche, publiés ou non, émanant des établissements d'enseignement et de recherche français ou étrangers, des laboratoires publics ou privés. 
Evaluating order acceptance policies for divergent production systems with co-production

Ludwig DUMETZ $^{1 *}$, Jonathan GAUDREAULT ${ }^{1}$, André THOMAS ${ }^{2}$,

Nadia LEHOUX ${ }^{1}$, Philippe MARIER ${ }^{1}$, Hind EL-HAOUZI ${ }^{2}$

${ }^{1}$ FORAC Research Consortium, Université Laval, Québec, Canada

jonathan.gaudreault@,forac.ulaval.ca; nadia.lehoux@,cirrelt.ca;

philippe.marier@ulaval.ca; 1udwig.dumetz@cirrelt.ca)

${ }^{2}$ CRAN, Centre de Recherche en Automatique de Nancy, France

(andre.thomas@,univ-lorraine.fr; hind.el-haouzi@univ-lorraine.fr)

* Corresponding author 


\title{
Evaluating order acceptance policies for divergent production systems with co-production
}

\begin{abstract}
The impacts of using different order acceptance policies in manufacturing sectors are usually well known and documented in the literature. However, for industries facing divergent processes with co-production (i.e. several products produced at the same time from a common raw material), the evaluation, comparison, and selection of policies are not trivial tasks. This paper proposes a framework to enable this evaluation. Using a simulation model that integrates a custom-built ERP, we compare and evaluate different order acceptance policies in various market conditions. Experiments are carried out using a case from the forest products industry. Results illustrate how and when different market conditions related to divergent/co-production industries may call for Available-To-Promise (ATP), Capable-To-Promise (CTP), and other known strategies. Especially, we show that advanced order acceptance policies like CTP may generate a better income for certain types of market and, conversely to typical manufacturing industries, ATP performs better than other strategies for a specific demand patterns.
\end{abstract}

Keywords: Order acceptance policies, discrete event simulation, co-production systems, divergent production systems, decision support systems.

\section{Introduction}

For traditional manufacturing industries (e.g. assembly), the behaviour induced by mainstream planning and order acceptance policies such as Available-To-Promise $(A T P)$ or Capable-To-Promise $(C T P)$ is well known and documented (Slotnick, 2011). The literature typically shows the trade-off between accepting orders and losing sales (Altendorfer and Minner, 2015). However, it is very difficult to assess the impact of such policies for industries with divergent processes and where several co-products and by-products are made from the same raw material at the same time (i.e. co-production, see Öner and Bilgiç [2008]). We denote an important difference between these two terms. A co-product is a valuable product that we can produce when producing our first 
choice of products. By-products are unintended and inexorably produced when producing any product. By-products are lower-value products like wood chips in the lumber industry, in contrast to co-products that can be lumber products. Co-production generates inventories for products that can be hard to sell or have less value. The agrofood industry, the oil industry, the forest products industry, and natural resources in general, are all examples of manufacturing systems facing divergent/co-production processes.

For this context, selecting a production planning and an order acceptance policy (based on CTP, ATP, or others) and determining how it should be managed (e.g. planning horizon, replanning frequency, etc.) is not a tremendous task. The answer will depend on the co-production structure of the processes, the presence or absence of alternative production processes, and, of course, on market considerations.

With this in mind, we developed a simulation-based framework that integrates a custom-built ERP system. It allows comparing and evaluating different order acceptance policies according to the business environment and market conditions. By testing different scenarios using the framework, one can answer questions concerning the order acceptance policy to implement, the planning horizon and planning frequency to apply, and the impact all the configurations may have on the financial performance of the company.

With the help of this framework, we were able to simulate different approaches suitable for the North American lumber industry. This industry is a very interesting case of divergent process with co-production as it produces and sells both very standard commodity products as well as other products specifically designed for certain customers. Our experiments led to recommendations that would have been seen as counter-intuitive without any experimentations. For example, we show that advanced 
order acceptance policies like CTP may generate a better income for certain types of market and, conversely to typical manufacturing industries, ATP performs better than other strategies for a specific demand patterns.

The remainder of the paper is organised as follows. Section 2 presents preliminary notions regarding decision-making models for divergent production systems with co-production, as well as a description of the lumber manufacturing industry. Section 3 introduces the simulation framework and presents a first experiment conducted to verify and validate the model. Section 4 highlights how a lumber company may perform under various market conditions when adopting different production planning and order acceptance policies. Section 5 concludes the paper.

\section{Preliminary notions}

\subsection{Divergent processes with co-production}

In some industries, a common raw material may conduct to multiple finished and semifinished products. This is called a divergent process (Arnold, Chapman, and Clive [2012]). When the production process produces these co-products at the same time, then it is said to be a divergent process with co-production (Gaudreault et al. [2011]). Facing both divergent processes and co-production makes the production planning especially challenging. As a result, the development of decision-making tools to support this specific context becomes necessary.

A first example of an industry dealing with divergent processes is the food sector. Ahumada and Villalobos (2009) listed more than fifty models that were developed, used or tested to plan all the activities of the food supply chain from farm to table (Aramyan et al. 2006). Another example is the oil industry. Pinto, Joly, and Moro (2000) proposed an overview of linear programming and nonlinear programming models as well as 
commercial tools created to support planning and scheduling in oil refineries. Taskin and Unal (2009) looked at the float glass manufacturing process and developed a decision-support system at the tactical level for a company in Turkey. They also mentioned several works that proposed models to better plan the production of this industry (Liu and Sherali [2000], Crama et al. [2001]) and co-production systems in general (Bitran and Leong [1992], Bitran and Gilbert [1994], Joly, Moro and Pinto. [2002]). Finally, Kallrath (2002) studied planning and scheduling approaches for the case of the chemical industry. Even though those models are useful for all the industries mentioned, they didn't focus on comparison between different order acceptance policies.

\subsection{The case of the lumber industry}

Due to the limited availability of wood fibre, the heterogeneity of the material in terms of inherent characteristics, quality, physical dimensions (diameter, length, etc.), complex transformation processes, and a divergent product flow, sawmilling is a difficult-to-manage process. In Canada, $90 \%$ of the forest belongs primarily to the government which decides on the quantity of wood to allocate to each forest products company (see the Annual report: « The state of Canada's forests » from the Natural Resources Canada). In the province of Quebec, this supply doesn't cover all the company's needs, the remainder has to be satisfied via auctions and private forests (i.e. unreliable supply). As a result, a forest products company facing an increasing demand will not necessarily be able to increase its procurement accordingly.

Producing lumber involves a three-phase manufacturing process (Gaudreault et al. 2010). It first encompasses a sawing unit responsible for sawing logs into green rough lumber according to a certain cutting pattern. At this stage, the lumber produced 
varies in terms of quality (grade), length, and dimensions. The lumber must then be dried using a kiln unit so as to reduce its moisture content. According to Yan, De Silva, and Wang (2001), the drying operation is crucial to reduce biological damage, increase dimensional stability, and reduce transportation costs. Furthermore, this step is necessary for lumber use in the construction market (Wery et al. 2014). The final step is conducted by the finishing unit to obtain the desired surface and thickness.

Many optimisation models have been developed to better support lumber production planning. Marier et al. $(2011 ; 2014)$ proposed a tactical mixed-integer programming (MIP) model that integrates the three production phases (sawing, drying, finishing) into a Sales and Operations Planning (S\&OP). It is used to correlate sales, marketing, procurement, production, so as to create an annual plan that takes different product families into consideration. A similar tactical planning model was proposed by Singer and Donoso (2007) for the Chilean sawmilling industry. At the detailed operational level, Gaudreault et al. (2010) proposed three MIP models used to plan/schedule sawing, drying, and wood finishing operations. The objective function allows maximising production value and/or minimising order lateness. A basic coordination mechanism is provided to synchronise those plans. Improved coordination mechanisms are proposed in Gaudreault, Frayret, and Pesant (2009) and Gaudreault et al. (2012). A stochastic version of the sawing operations planning was developed by Kazemi-Zanjani, Ait-Kadi, and Nourelfath (2013). An improved version of the drying model was also proposed in Gaudreault et al. (2011).

\subsection{Evaluating order acceptance policies}

The previous sub-sections exposed that many researchers have proposed mathematical models which aim to plan/optimise divergent processes with co-production. However, 
companies do not necessarily know the best way to integrate these mathematical models within their management processes nor which of these models would be the most efficient one regarding their market contexts.

The same situation applies for order acceptance policies. Order acceptance policies define the rules used to accept or reject an order depending on the product availability and the production capacity of the company. The best-known strategies are available-to-promise (ATP) and capable-to-promise (CTP), see APICS (2012). Many researchers have spent time studying those acceptance policies such as Vollmann, Bery and Whybark (1997) and Taylor and Plenert (1999) that propose a heuristic technique (Finite Capacity Promising) which calculate due dates for customer orders. More recently Slotnick (2011) proposed a literature review on order acceptance and scheduling. The study focuses on the balance between revenue and costs of processing of accepting an order and how to schedule them. Wang et al. (1994) developed some rules to accept or refuse an order in a job-shop environment based on profit. More recently, Moses et al. (2004) proposed a real-time order promising model based on the CTP in a make-to-order environment. The model takes into account the capacity requirement and generates due dates before scheduling orders. Pibernik and Yadav (2009) developed a combination of both ATP and CTP (Advanced Available-ToPromise $A A T P$ ) in a make-to-stock environment while considering a stochastic demand. Kirche and Srivastava (2015) developed a real-time order management model that takes into account due dates and possible negotiations with penalties in a make-to-order environment.

Order acceptance policies received less attention for industries facing both divergent and co-production processes. Kilic et al. (2010) proposed a two-bound method for orders acceptance/rejection in the food industry in a stochastic environment, 
based on the resource level. It accepts every order when the resource level is high enough. If resource level is low, accept an order is permitted only if future orders with higher value are not possible. They compare the method to a First Come Fist Served (FCFS) approach. Azevedo, D’Amours, and Rönnqvist (2012) proposed an order acceptance model for the Canadian softwood lumber industry, but for make-to-stock environment only. Islam (2013) studied order-promising and production planning methods for sawmills. He developed a MIP model that included ATP calculation and production planning while considering two types of demand: contract and spot market. However, only one variant $A T P$ calculation is used without any comparison with other order acceptance policies.

\subsection{Assessment with simulation}

Comparing different production strategies or acceptance policies for various market conditions may be facilitated by the use of simulation. El Haouzi, Thomas, and Petin (2008) used discrete-event simulation to compare different manufacturing systems for a company implementing Demand Flow Technology (DFT). Abdel-Malek, Kullpattaranirun, and Nanthavanij (2005) also exploited simulation to compare different supply chain outsourcing strategies, using the inventory levels and the total cost as performance indicators. Jerbi (2014) used simulation, coupled with optimisation, to assess allocation strategies of a forest value chain. Many works highlighted the possibilities of combining multi-agent systems with simulation. Lemieux (2010) mentioned several ones, including Julka, Srinivasan, and Karimi (2002) as well as Garcia-Flores and Wang (2002) who provided frameworks for the simulation of supply chains in the chemical industry. Mourtzis, Doukas, and Psarommatis (2015) integrated different optimisation methods to design and operate manufacturing networks subject to 
various constraints (economical and environmental) and demand fluctuation. Some criteria like cost, time, environmental impact and quality are highlighted. They used discrete-event simulation to examine the complexity of the network and to compare different network configuration alternatives. Renna (2015) developed a multi-agent architecture to model the decentralized structure of a production network. He then used the model to study diverse coordination strategies between network members. The author demonstrated that market conditions influence the performance of both the customer and the supplier. Finally, Raaymakers, Bertrand, and Fransoo (2000) used simulation to accept or refuse an order in a chemical company depending on the maximal capacity of the work centre. They showed that simulation is an efficient tool to compare and evaluate order acceptance strategies.

\subsection{Summary}

The literature showed that some models have been developed and methods used over the years to better plan production activities and order acceptance. Nevertheless, to the best of our knowledge, there are still no studies that compare diverse order acceptance policies for divergent/co-production process industries depending on market conditions. That is the challenge we aim to address in the next section.

\section{Proposed simulation framework}

This section introduces a generic framework developed to evaluate and compare different order acceptance policies according to a certain production context and diverse market conditions.

A conceptual representation of the framework is shown in Figure 1. The simulation process is carried out as follows: Orders are first generated according to a Poisson distribution (Ben Ali et al., 2014) and a given demand lead-time distribution 
(i.e. time between the order arrival and the required delivery date, (see Arnold et al. [2012]). Each order can next be either accepted or rejected according to a policy (ATP, $C T P$, or other ones). If the order is accepted, it "waits" until there is material availability and a delivery date associated with it. It is then shipped. To provide support for inventory management, production planning, and $A T P$ and $C T P$ calculations, a custombuilt ERP system has been developed using the C\# programming language and connected to the simulation tool. In particular, this custom-built ERP uses a mathematical model from Marier et al. (2014) and the Cplex optimisation solver for lumber production planning.

\section{INSERT Figure 1 HERE}

The next sub-section explain how the simulation analyst can configure and use the framework to assess different order acceptance policies.

\subsection{Configuring the framework}

Instead of implementing/coding $A T P$ and $C T P$ explicitly in our framework, we provide the simulation analyst with a set of more generic parameters that allow configuring the system in order to adopt many ATP variants, CTP variants, or other order acceptance policies of its choice. Those generic parameters that allow defining various detailed operations planning and orders acceptance policies are:

- Length of the production planning horizon;

- Re-planning frequency;

- After planning/replanning to satisfy orders, should we use still available capacity according to target previously established at the tactical level? 
- Is it mandatory when planning/replanning to continue satisfying previous commitments (make them hard constraints)?

- When a new tentative order arrives, are we allowed to re-plan (update the production plan) in order to try to satisfy it?

- Should we accept an order even though the quantity is not available according to our production plan and current commitments?

Setting the last parameter to "yes" allows implementing "dumb" strategies ('accept all orders') which can be used as a baseline to compare with other more advanced strategies. By default, an order of size Q is accepted only if:

$$
\mathrm{Q} \leq \mathrm{I}+\sum_{\mathrm{t}=\text { now }}^{\mathrm{D}-1}\left(\mathrm{P}_{\mathrm{t}}-\mathrm{E}_{\mathrm{t}}\right)-\max _{\mathrm{D} \leq \mathrm{t} \leq \mathrm{T}}\left\{\sum_{\mathrm{k}=\mathrm{D}}^{\mathrm{t}}\left(\mathrm{E}_{\mathrm{k}}-\mathrm{P}_{\mathrm{k}}\right)\right\}
$$

Where $\mathrm{D}$ is the order due date, $\mathrm{T}$ the simulation horizon, I the current inventory, $\mathrm{P}_{\mathrm{t}}$ the production at period $\mathrm{t}$, and $\mathrm{E}_{\mathrm{t}}$ the previous commitments for period $\mathrm{t}$.

It is also possible to configure the system to accept orders only if the product is already in inventory (we call that policy 'stock').

Different combinations of the other parameters allow implementing a large variety of strategies, from "plan once a week without taking demand into account" to advanced approaches such $A T P$ or $C T P$. It is also possible to define different strategies for different product families, such as a mixed approach using ATP for commodity product orders and CTP for customised products.

Finally, the simulation analyst can plug-in the production planning algorithm of its choice.

\subsection{Verification and validation of the model}

Experiments were carried out in order to perform verification and validation of the 
model (see Sargent (2004)). By definition, model verification concerns the way the system implementation is error-free (i.e. verification to ensure that the flow equilibrium is always satisfied). Model validation checks whether the model fits the real-life system or not. In order to do this, different scenarios were tested on a case small enough to anticipate the results.

Table 1 below shows the full-factorial design used for this purpose. It defines parameter values for the order acceptance policy, the production planning policy, and market conditions. The values used in the simulation were inspired by the standards typically found in Canadian sawmills.

(Table 1)

A total of 600 scenarios were defined. The simulation horizon covered a full year, each day being divided into 2 production shifts (periods) of 7 hours of work. Enough raw materials were available for the actual production capacity. Responses of the simulation were related to the volume of sales and the average inventory. We needed 15 replications to obtain a significant confidence interval (confidence level of $95 \%)$. The time needed to run one scenario considering the confidence interval was around 50 seconds, except for the $C T P$ case which was around 10 minutes.

\subsubsection{Impact of the length of the planning horizon}

Figure 2 shows the impact of the length of the planning horizon on the total volume of orders accepted and on the average inventory level. The parameters of the model are set for a demand intensity corresponding to $130 \%$ of the production capacity, a triangular demand lead-time distribution $(1,2,3)$, and a re-planning frequency of 1 week. Results are shown for the different acceptance policies investigated (ATP, CTP, Stock, and 
AcceptAll). AcceptAll is utopic because accepted volume exceeds the total capacity, hence generating backorders. However, it defines an upper bound for the total volume of sales and a lower bound for the inventory level. It is the same idea as with the Stock policy, which provides the lower bound for the total volume of accepted orders and the upper bound for inventory levels when the length of the planning horizon is high enough to take the entire demand into account.

\section{INSERT Figure 2 HERE}

If we look at the volume of orders accepted for $A T P$ and $C T P$, as expected, they are greater than for Stock when we reach a planning horizon that takes into account the entire demand. Volume of accepted orders for ATP and CTP increases with the length of the planning horizon (the shorter the horizon, the more we need to refuse some orders because our production plan and $A T P$ do not reach that point). In our specific case, with a cumulative lead time of 4 weeks and a replanning frequency of 1 week, there is no need to have a planning horizon superior to 4 weeks since no order can be received after the fourth week (although industry often uses a longer planning horizon to have a better visibility, as mentioned by Arnold, Chapman, and Clive (2012)). This result was expected (see Vollman, Berry, and Whybark (1997)) and contributed to establish the validity of the model.

Conversely, the inventory level associated to ATP and CTP policies decreases when the length of the planning horizon increases, until we reach a planning horizon of four weeks. This result is also coherent.

Finally, we note that for $A T P$ and $C T P$ policies, even though the accepted volume is only slightly higher than the Stock policy (as the global production capacity 
remains the same), the reduction of the average inventory is significant (around 58.5\% for a planning horizon of four weeks).

\subsubsection{Impact of demand intensity}

We first recall that demand intensity is the total demand expressed as a percentage of the total production capacity. Figure 3 shows the total volume of accepted orders and the average inventory according to the demand intensity.

As expected, the greater the demand intensity is, the greater the total volume of accepted orders will be. This is true until we reach a point where the entire production can be sold. For the specific case reported, it was reached at around 300\% (the volume of accepted orders is then equalled to the global production capacity). An intensity of $100 \%$ of the production capacity would thus not be enough (due to the stochastic environment, demand for some specific products would be less than their production volumes; some orders would have due date outside the simulation horizon).

\section{INSERT Figure 3 HERE}

Regarding the average inventory level, the greater the intensity of demand is, the smaller the average inventory has to be. This is true for any policy. However, the greater the intensity is, the bigger the difference between $A T P / C T P$ and Stock policies is.

We recall that AcceptAll policy may look attractive (less inventory). However, there is a huge number of late deliveries and therefore customer satisfaction is very poor. By comparison, on-time delivery reaches 39\% for AcceptAll, against $100 \%$ for Stock, ATP, and CTP policies. 


\section{Using the framework to select the best policy according to market conditions}

In this section, we show how the simulation model was used to determine which strategy should be followed by a company according to specific market characteristics. We will thereby measure the company's performance, in terms of volume of sales, inventory levels, and total income, when a certain order acceptance strategy is applied and some market conditions faced. Those results have been established for a particular context (i.e. the forest sector) and based on specific values (i.e. reflecting the sawmilling industry). Those results should not be generalised to any types of industry nor parameter values. On the other hand, the proposed framework could be adapted and used for other industries facing divergent processes and co-production.

\subsection{Experiments}

The simulation parameters remained the same as the ones used for model validation, except for the following points: the simulation horizon covers two years, and a warm-up period of one year is set (this allowed reaching a steady state situation). A total of 240 scenarios were simulated with a significant number of replications to have a desired confidence interval (confidence level of 95\%).

\subsection{Results and Analysis}

\subsubsection{Commodity-product market}

We first compare how the different policies perform in a $100 \%$ commodity-product market. For better readability, the error bars are shown every $5 \%$ on the $x$-axis. Figure 4 shows the volume of sales (number of orders) according to the demand intensity for different order acceptance policies (Stock, ATP, and CTP). 


\section{INSERT Figure 4 HERE}

When demand is low, CTP accepts more orders than ATP (i.e. it pays to plan the production again according to customers' needs, otherwise opportunities are missed). This is the same result we would get in typical manufacturing system with no divergent / co-production processes. However, the particularities of our divergent/co-production process arise when demand intensity reaches $125 \%$. From that point, ATP outperforms CTP. This is explained by the following reason. When demand intensity reaches $125 \%$, demand is significant enough to allow the sale of all the production planned according to forecasts. As for CTP, we recall it changes the production processes used to best fit the most recent orders. By changing the manufacturing process used, the co-products produced change too, and nothing assures that in the short term, demand will exist for these new co-products. On the other hand, ATP retains the same production plan that was established using forecasts and when demand is high, that volume is easily sold. Therefore, what is an advantage when demand is low becomes a disadvantage when demand is high. This situation is a good example of the specific impact and difficulties associated to process embedding mandatory co-production. Furthermore, forest products companies in North-America have frequently to deal with this extra demand and even though they would acquire more capacity to better satisfy a demand increase, they would still not be able to increase their wood fibre procurement accordingly (i.e. limited raw material procurement).

In order to show how the $A T P / C T P$ trigger point is affected by forecast accuracy, Figure 5 provides the same results as Figure 4, but for a situation with inaccurate forecasts. In the previous experiments, planning was carried out using a forecast supposing that $80 \%$ of the most popular produced products would form $100 \%$ 
of demand. In this new experiment, we badly forecast that $20 \%$ of the less popular products will form $100 \%$ of the demand; this is obviously not the case.

\section{INSERT Figure 5 HERE}

The $A T P / C T P$ trigger point is shifted to the right in comparison to Figure 4 because the ATP policy needs a greater demand intensity so that more of the lowdemand produced products can be used to fulfil the demand.

\subsubsection{Consideration of a market with customised products}

We previously compared different policies in a market composed of $100 \%$ commodity products. In North America, lumber are standardised by the National Lumber Grades Authority (NLGA), which allows for the products to be considered as a commodity. However, in recent years, the demand for customised product has increased while in Europe customised products represent the main part of the market.

In the next experiments, some additional parameters and a new order acceptance policy (a mixed approach called $M I X$ that uses $A T P$ for commodity product orders and CTP for customised products) are included to represent these two different markets.

Figure 6 shows the results for a market composed of $70 \%$ commodity products and $30 \%$ customised products.

INSERT Figure 6 HERE

$C T P$ can again accept more orders than $A T P$ as it can accept orders for customised products. However, when demand intensity is high enough, ATP is still able to use its entire capacity considering demand for commodity products only. ATP 
becomes even better than CTP for very high demand (around 190\% demand intensity) for the same reason explained previously.

This figure also introduces the $M I X$ policy. We recall that $M I X$ policy uses the ATP to satisfy demand for commodity products. It only calls re-planning when there is demand for customised products. When demand is very low, ATP is outperformed by $M I X$ (for the same reason $A T P$ is outperformed by $C T P$ ). When demand intensity reaches $100 \%, M I X$ performs better than $C T P$ because it benefits from the effect of good forecasts: $M I X$ uses $A T P$ for commodity products and then keeps the same production plan that was established using forecast. When demand is high, that volume is easily sold. At a very high demand intensity level, the three policies are almost equal.

\subsubsection{Impact of the strategies on inventory}

All the previous analyses focused on the volume of sales according to the demand intensity for each strategy, without considering the average inventory over the year. However, it needs to be considered when defining company policies. The following figure shows the impact of the different policies on the inventory level. We choose to represent the average inventory for a market composed of $90 \%$ commodity products and $10 \%$ customised products with an accurate forecast.

\section{INSERT Figure 7 HERE}

For any policy, the average inventory decreases with an increase of the intensity of the demand. However, a greater demand intensity involves a larger difference between $A T P / C T P$ and Stock policies. We observed previously that for a very high demand intensity, the number of accepted orders by an $A T P$ or a CTP policy is equal. In contrast, the average inventory for the CTP policy is smaller than for the ATP policy 
because the CTP policy can trigger a new plan each time an order is received. As a result, the product spends less time in stock. Finally, we recall that the AcceptAll policy is utopic (we accept orders we will not be able to fill) and is only used for comparison purposes.

If the market changes and some customised products are on demand, we observe the same trend as previously for the average inventory: the greater the intensity, the bigger the difference between $A T P / C T P / M I X$ and Stock policies.

\subsection{Managerial insights}

The proposed framework aims to guide the decision maker in the policy to apply according to the market conditions he is facing. However, beyond the performance indicators analysed, the fact remains that changes to sales revenues associated with customised products and market conditions can be significant. It is therefore interesting to show the effect of such a value and how it can guide the decision maker in his choice.

\subsubsection{Margin and total income}

The revenues associated to customised products will usually be greater than the ones obtained for standard/commodity products. In North America, a customised product in the sawmilling sector can be more expensive by about 10 to $20 \%$. For other industries, a customised product can be more expensive by $50 \%$ or more. To illustrate the importance of the choice of the strategy according to the market conditions, the figure below shows the total income for each strategy according to the demand intensity. In this example, a unit price of $10 \$$ has been set for the commodity product and a unit price of $12 \$$ for the customised product. As expected, the difference in revenues associated to commodity and customised products increases the gap between approaches. 
INSERT Figure 8 HERE

Moreover, MIX and CTP show a better total income than ATP or Stock. It is interesting to see the possible margin to gain depending on the businesses involved as well as the customised product requested.

\subsubsection{Decision chart}

In order to facilitate analysis, we propose that decision makers use a decision chart synthesising the previous results (Figure 9). Depending on the demand intensity and the proportion of orders for customised (versus commodity) products, this chart identifies the policy that maximises profit.

We recall that this decision graph has been established for a particular context (i.e. the forest sector) and based on specific values (i.e. reflecting the sawmilling industry). The chart should rather be viewed as an "easy-to-read" diagram that allows a sawmill company to rapidly understand all the possibilities the different order acceptance policies may offer depending on its business context. It would have to be recomputed each time major changes occur.

\section{INSERT Figure 9 HERE}

\section{Conclusion}

This article proposed a simulation framework to compare and evaluate different order acceptance policies for divergent production systems with co-production. The simulation tool developed encompasses a custom-built ERP system that covers inventory management, lumber production, planning algorithms, and $A T P / C T P$ calculation. After being verified and validated, the tool was used to perform different 
studies for North-American lumber production context. By testing different scenarios, we were able to measure the impact of well-known order acceptance policies on the performance of a sawmilling company.

It allowed us to illustrate that the best strategy to use in divergent with coproduction context often differs from the one that would have been optimal in a classical manufacturing (e.g. assembly) context. As an example, we showed that although $C T P$ (capable-to-promise) allows us to have a better income in certain types of markets where demand is very low, ATP (available-to-promise) performs better in some other cases. Moreover, we showed that using a mixed strategy when the market was composed by commodity products and customised products is a better option. Even though the results should not be generalised to all types of industry nor parameter values, the proposed framework could be used for other industries facing divergent processes and co-production.

In future work, this simulation framework could be used to perform a more complex study. For example, it could be adapted to take into account stochastic events in production and raw material procurement so as to propose guidelines for more agile operations management driven by demand. The framework could also allow simulating different coordination mechanisms between the tactical and operational planning level, as well as between the different departments (e.g. raw material procurement, production and sales).

\section{References}

Abdel-Malek, L. Kullpattaranirun, T., \& Nanthavanij, S. (2005). A framework for comparing outsourcing strategies in multi-layered supply chains. International Journal of Production Economics, 97, 318-328. 
Ahumada, O., \& Villalobos, J. R. (2009). Application of planning models in the agrifood supply chain: A review. European Journal of Operational Research, 196(1), 1-20.

Altendorfer, Klaus, and Stefan Minner. (2015) Influence of order acceptance policies on optimal capacity investment with stochastic customer required lead times. European Journal of Operational Research 243.2, 555-565.

APICS. (Ed.) (2008) (twelfth edition ed.).

Aramyan, L., Ondersteijn, C. J., Van Kooten, O., \& Lansink, A. O. (2006). Performance indicators in agri-food production chains Quantifying the agri-food supply chain Springer 49-66.

Arnold, J.R.T., Chapman, S., \& Clive, L. (2012). Introduction to Materials Management. Pearson, Seventh Edition.

Azevedo, R. C., D’Amours, S., Rönnqvist, M. (2012): Advances in Profit-Driven Order Promising for Make-To-Stock Environments - A Case Study With a Canadian Softwood Lumber Manufacturer. International Journal of Production Economics (submitted).

Ben Ali, M., Gaudreault, J., D'Amours, S., \& Carle, M.-A. (2014). A Multi-Level Framework for Demand Fulfillment in a Make-to-Stock Environment - A Case Study in Canadian Softwood Lumber Industry. MOSIM. Nancy

Bitran, G. R., \& Gilbert, S. M. (1994). Co-production processes with random yields in the semiconductor industry. Operations Research, 42(3), 476-491.

Bitran, G. R., \& Leong, T. Y. (1992). Deterministic approximations to co-production problems with service constraints and random yields. Management Science, 38(5), 724-742.

Crama, Y., Pochet, Y., \& Wera, Y. (2001). A discussion of production planning approaches in the process industry (No. CORE Discussion Papers (2001/42)). UCL.

El Haouzi, H., Thomas, A., \& Pétin, J.-F. (2008). Contribution to reusability and modularity of Manufacturing Systems Simulation Models: application to distributed control simulation within DFT context. International Journal of Production Economics, 112 (1), 48-61.

Garcia-Flores, R., \& Wang, X. (2002). A multi-agent system for chemical supply chain simulation and management support. Or Spectrum, 24(3), 343-370. 
Gaudreault J, Frayret. JM., Rousseau, A., \& D'Amours, S. (2011). Combined planning and scheduling in a divergent production system with co-production: A case study in the lumber industry. Computers and Operations Research, 38(9), 12381250.

Gaudreault J, Frayret. JM., \& Pesant, G. (2009). Distributed search for supply chain coordination. Computers in Industry, 60(6), 441- 451.

Gaudreault J, Pesant. G, Frayret JM, \& D’Amours S. (2012). Supply chain coordination using an adaptive distributed search strategy. IEEE Transactions on Systems Man and Cybernetics Part C, 42(6), 1424- 1438.

Gaudreault, J., Forget, P., Frayet, J.-M., Rousseau, A., Lemieux, S., \& D'Amours, S. (2010). Distributed operations planning in the lumber supply chain: models and coordination. International Journal of Industrial Engineering-Theory Applications and Pra, 17(3), 168-189.

Islam, M. S. PhD: (2013) Order promising and production planning methods for sawmills

Jerbi, W (2014). Intégration de l'optimisation et de la simulation pour l'élaboration et l'évaluation de politiques de production et de transport d'une chine logistique. M.Sc., Université Laval.

Joly, M., Moro, L., \& Pinto, J. (2002) Planning and scheduling for petroleum refineries using mathematical programming. Brazilian Journal of Chemical Engineering, 19:207-228,

Julka, N., Srinivasan, R., \& Karimi, I. (2002). Agent-based supply chain management: framework. Computers and Chemical Engineering, 26(12), 1755-1769.

Kallrath, J. (2002). Planning and scheduling in the process industry. OR spectrum, 24(3), 219-250.

Kazemi Zanjani, M., Ait-Kadi, D., \& Nourelfath, M. (s.d.). (2013) A stochastic programming approach for sawmill production planning. International Journal of Mathematics in Operational Research, Vol. 5, No. 1, 1-18.

Kilic, Onur A., et al. (2010) Order acceptance in food processing systems with random raw material requirements. OR spectrum 32(4), 905-925.

Kirche, E.T. and Srivastava, R. (2015) Order management with renegotiated due dates and penalty costs in an integrated supply chain. International Journal of Operations and Quantitative Management, Volume 21, Issue 2, 141-163. 
Lemieux, S. (2010). Simulateur multiagent d'un réseau de création de valeur : application à l'industrie forestière. $\mathrm{PhD}$ diss., Université Laval.

Liu, C. M., \& Sherali, H. D. (2000). A coal shipping and blending problem for an electric utility company. Omega, 28(4), 433-444.

Öner, S., \& Bilgic, T. (2008). Economic lot scheduling with uncontrolled coproduction. European Journal of Operational Research, 188(3), 793-810.Marier, P. (2011). Gestion intégrée des ventes et des opérations dans l'industrie du sciage. Expo-Conférence. Université Laval, Canada, Québec.

Marier, P., Gaudreault, J., \& Robichaud, B. (2014, Novembre 5-7). Implementing a MIP model to plane and schedue wood finishing operation in a sawmill: lessons learned. 10th International Conference of Modelling and Simuling-MOSIM'14.

Moses, S., Grant, H., Gruenwald, L., \& Pulat, S. (2004). Real-time due-date promising by build-to-order environments. International Journal of Production Research, $42(20), 4353-4375$.

Mourtzis, D., Doukas, M., \& Psarommatis, F. (2015). A toolbox for the design, planning and operation of manufacturing networks in a mass customisation environment. Journal of Manufacturing Systems, 36, 274-286.

Natural Resources Canada « The state of Canada's forests » 2015, Annual report

Pibernik, Richard, and Prashant Yadav. (2009) Inventory reservation and real-time order promising in a make-to-stock system. OR spectrum 31.(1), 281-307.

Pinto, J. M., M. Joly, and L. F. L. Moro. (2000) Planning and scheduling models for refinery operations. Computers \& Chemical Engineering 24.(9), 2259-2276.

Raaymakers, Wenny HM, J. Will M. Bertrand, and Jan C. Fransoo. (2000) The performance of workload rules for order acceptance in batch chemical manufacturing. Journal of Intelligent Manufacturing 11.(2), 217-228.

Renna, P. (2015) Coordination strategies to support distributed production planning in production networks. European Journal of Industrial Engineering, Volume 9, Issue 3, 366-394.

Sargent, Robert G. Validation and verification of simulation models. Simulation Conference. Proceedings of the 2004 Winter. Vol. 1. IEEE, 2004.

Singer, M and Donoso, P. (2007). Internal supply chain management in the Chilean sawmill industry. International Journal of Operations \& Production Management, 27(5), 524-541. 
Slotnick, Susan A. (2011) Order acceptance and scheduling: A taxonomy and review. European Journal of Operational Research 212.(1), 1-11.

Taşkın, Z. C., \& Ünal, A. T. (2009). Tactical level planning in float glass manufacturing with co-production, random yields and substitutable products. European Journal of Operational Research, 199(1), 252-261.

Taylor S. G. \& Plenert G. J. (1999). Finite Capacity Promising. Production and Inventory Management Journal. No.40(3),.50-56.

Vollmann, T., Berry, W., \& Whybark, D. (1997). Manufacturing planning and control for supply chain management. New-York: McGraw-Hill.

Wang, J., Yang, J. Q., \& Lee, H. (1994). Multicriteria order acceptance decision support in over-demanded job shops: a neural network approach. Mathematical and computer modelling, 19(5), 1-19.

Wery, J., Marier, P., Gaudreault, J., \& Thomas, A. (2014). Decision-making framework for tactical planning taking into account market opportunities (new products and new suppliers) in a co-production context. MOSIM. Nancy.

Yan, G. C. K., De Silva, C. W., \& Wang, X. G. (2001). Experimental modelling and intelligent control of a wood-drying kiln. International journal of adaptive control and signal processing, 15(8), 787-814. 
Table 1: Full-factorial design for the validation purpose

\begin{tabular}{|c|c|c|c|}
\hline & Parameters & Level & Value \\
\hline \multirow{3}{*}{ Market conditions } & $\begin{array}{l}\text { Demand } \\
\text { Intensity }^{1}\end{array}$ & 5 & $100,110,130,150,175 \%$ \\
\hline & $\begin{array}{l}\text { Demand lead } \\
\text { time }\end{array}$ & 2 & $\begin{array}{l}\text { Random } \quad \text { triangular } \\
(1,2,3) ; \quad \text { Random } \\
\text { triangular }(0.5,1,2)\end{array}$ \\
\hline & Order Size & 1 & $\begin{array}{l}50 \mathrm{MBFM}^{2} \text { (capacity of a } \\
\text { full-truck load) }\end{array}$ \\
\hline \multirow[b]{2}{*}{ Production planning policy } & $\begin{array}{l}\text { Re-planning } \\
\text { frequency }\end{array}$ & 3 & $1,2,3$ weeks \\
\hline & $\begin{array}{l}\text { Length of the } \\
\text { Planning } \\
\text { horizon }\end{array}$ & 5 & $2,2.5,3,3.5,4$ weeks \\
\hline Order acceptance policy & $\begin{array}{l}\text { Order } \\
\text { acceptance } \\
\text { policy }\end{array}$ & 4 & Stock, ATP, CTP, AcceptAll \\
\hline
\end{tabular}

${ }^{1}$ Demand intensity is a parameter we defined to express the total number of orders received as a percentage of the production capacity. It is used to define the arrival rate.

${ }^{2}$ MBFM stands for "thousand-foot board measure". Board-foot is the unit of wood volume measurement used in North America. 
Figure 1: Conceptual representation of the model

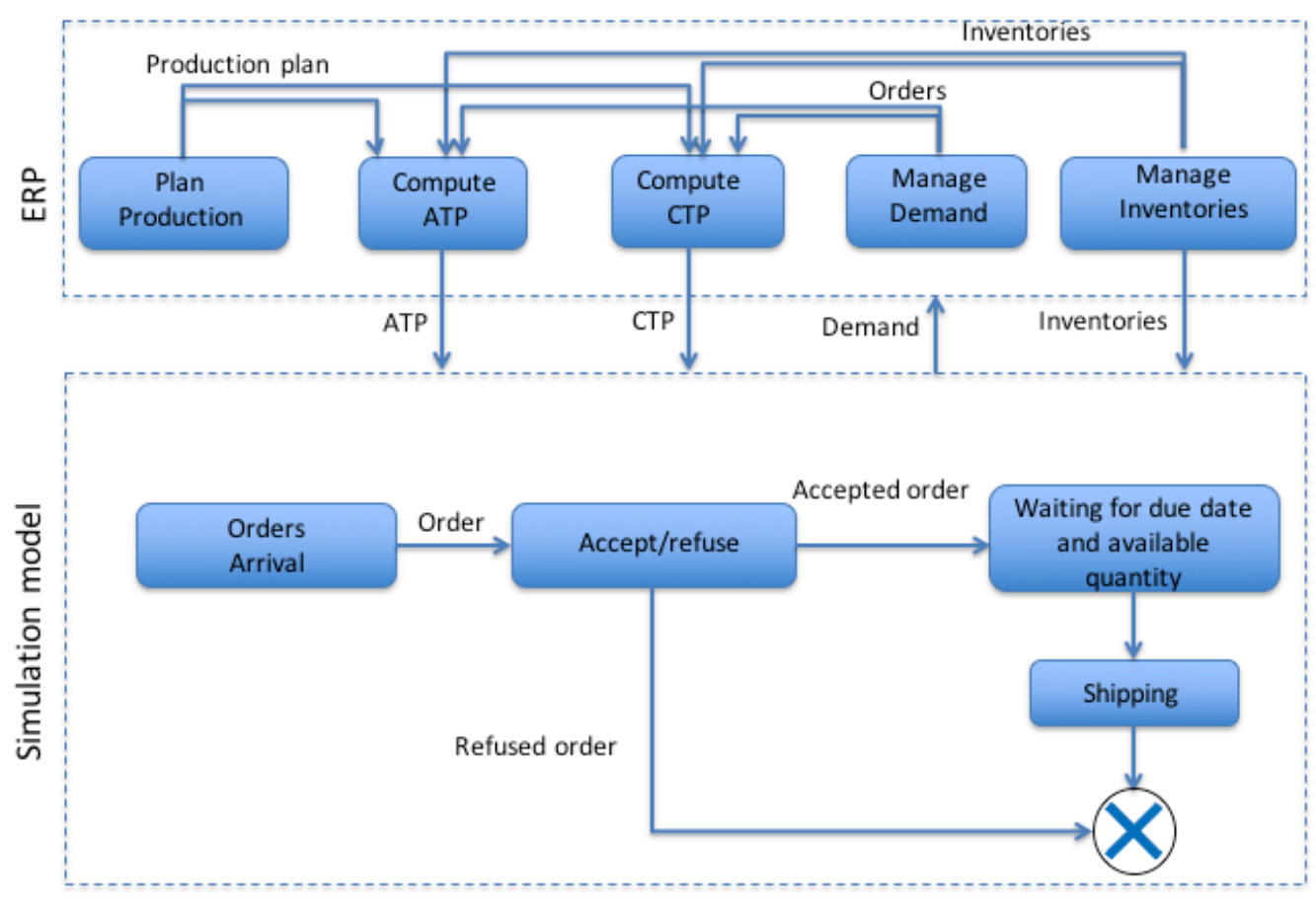

Figure 2: Impact of the length of the planning horizon (demand intensity $=130 \%$, replanning frequency $=1$ week)

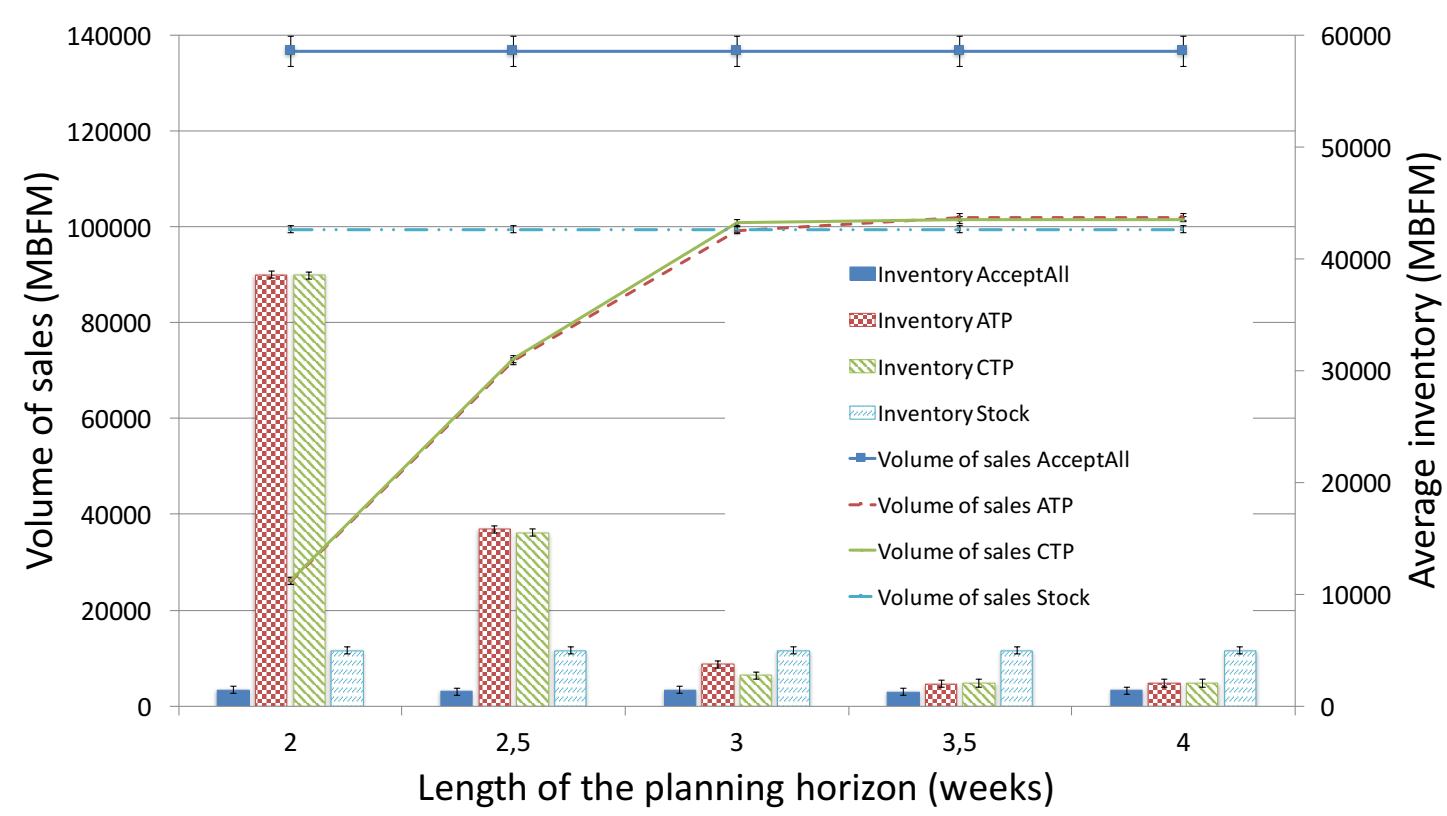


Figure 3: Impact of the demand intensity (length of the planning horizon $=4$ weeks; replanning frequency $=1$ week)

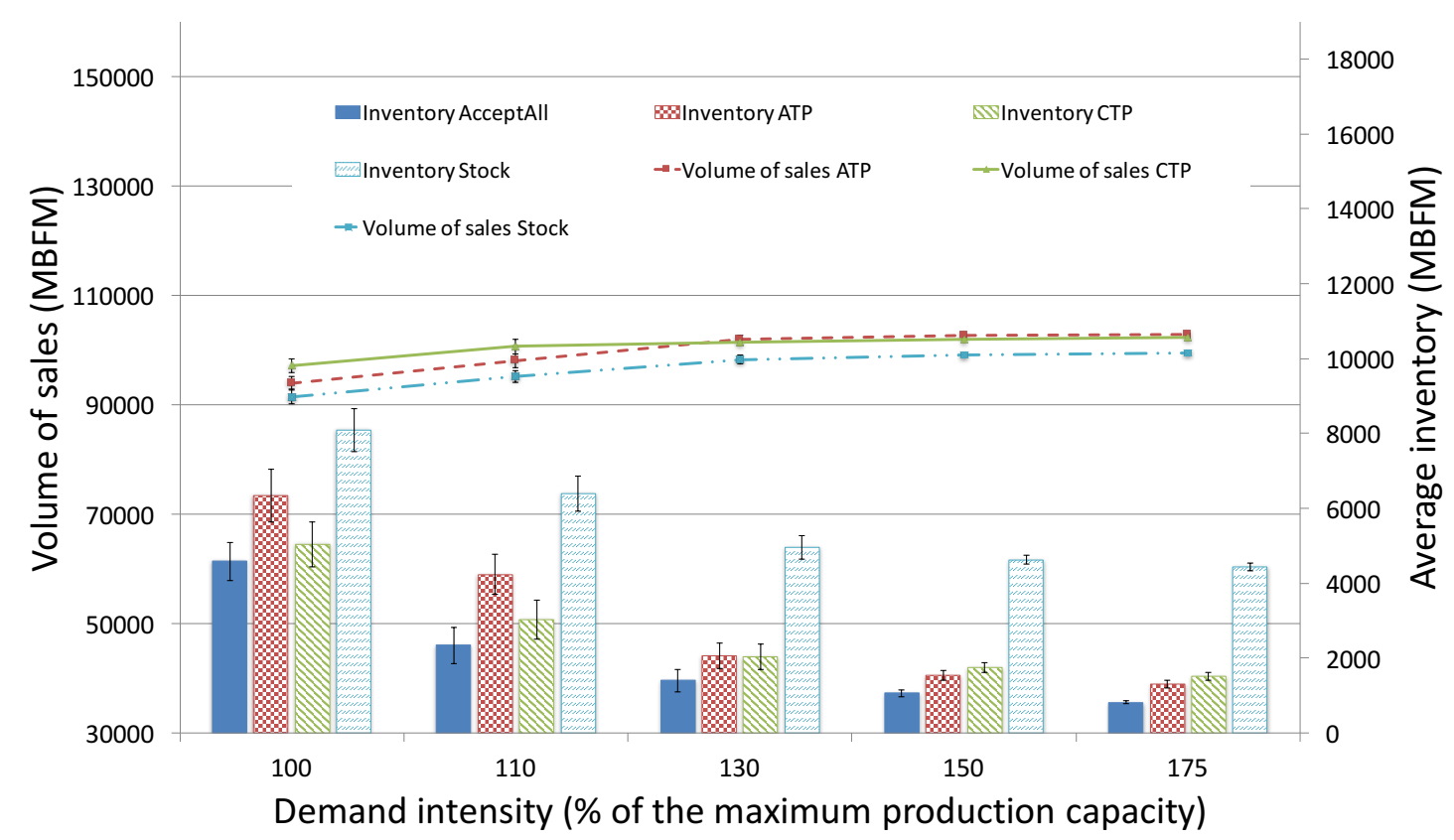

Figure 4: Volume of sales according to the demand intensity $($ Commodity product $=$ $100 \%$; accurate forecast; length of the planning horizon $=4$ weeks; replanning frequency $=1$ week)

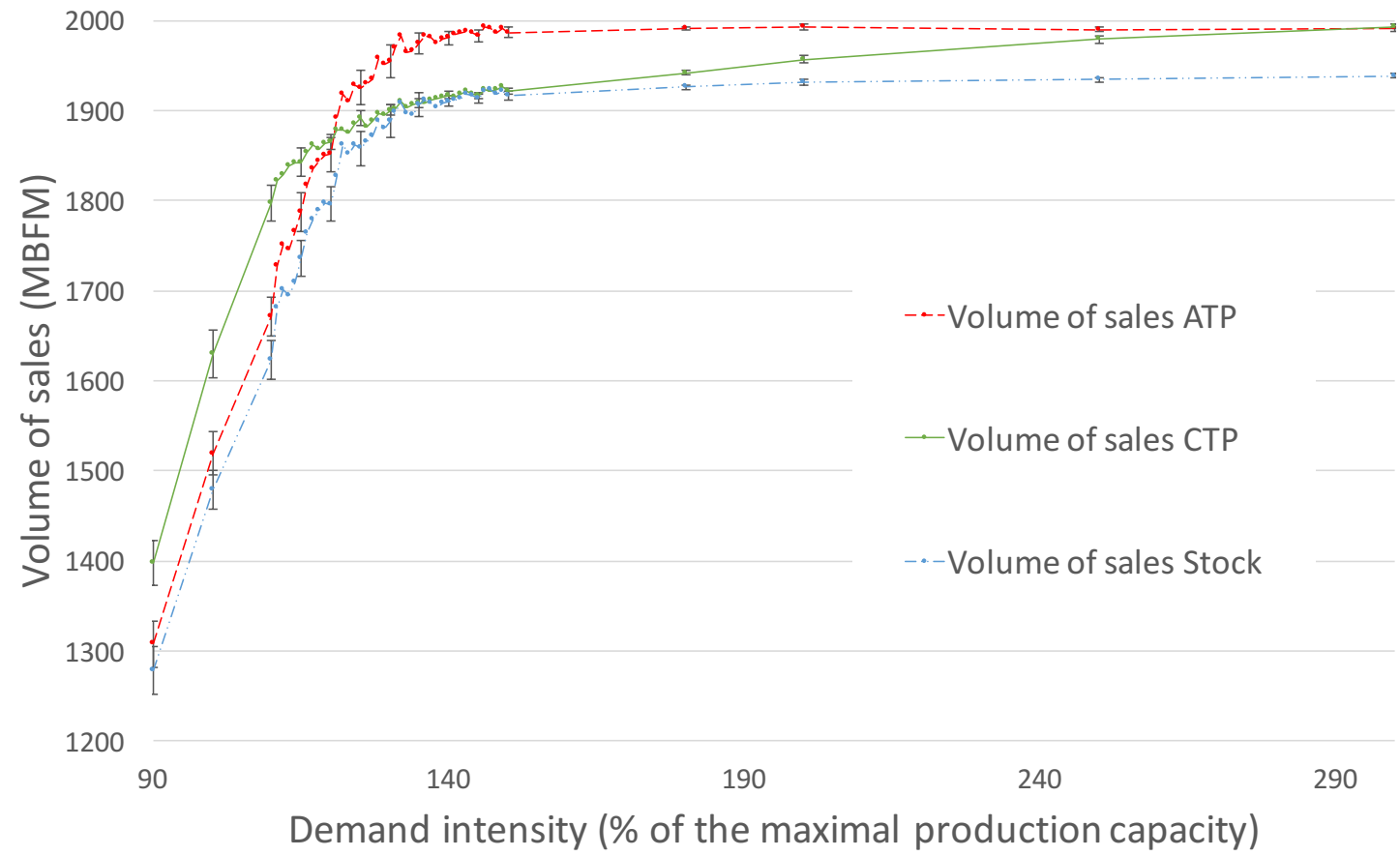


Figure 5: Volume of sales according to the demand intensity $($ Commodity product $=$ $100 \%$; inaccurate forecast; length of the planning horizon $=4$ weeks; replanning

$$
\text { frequency }=1 \text { week) }
$$

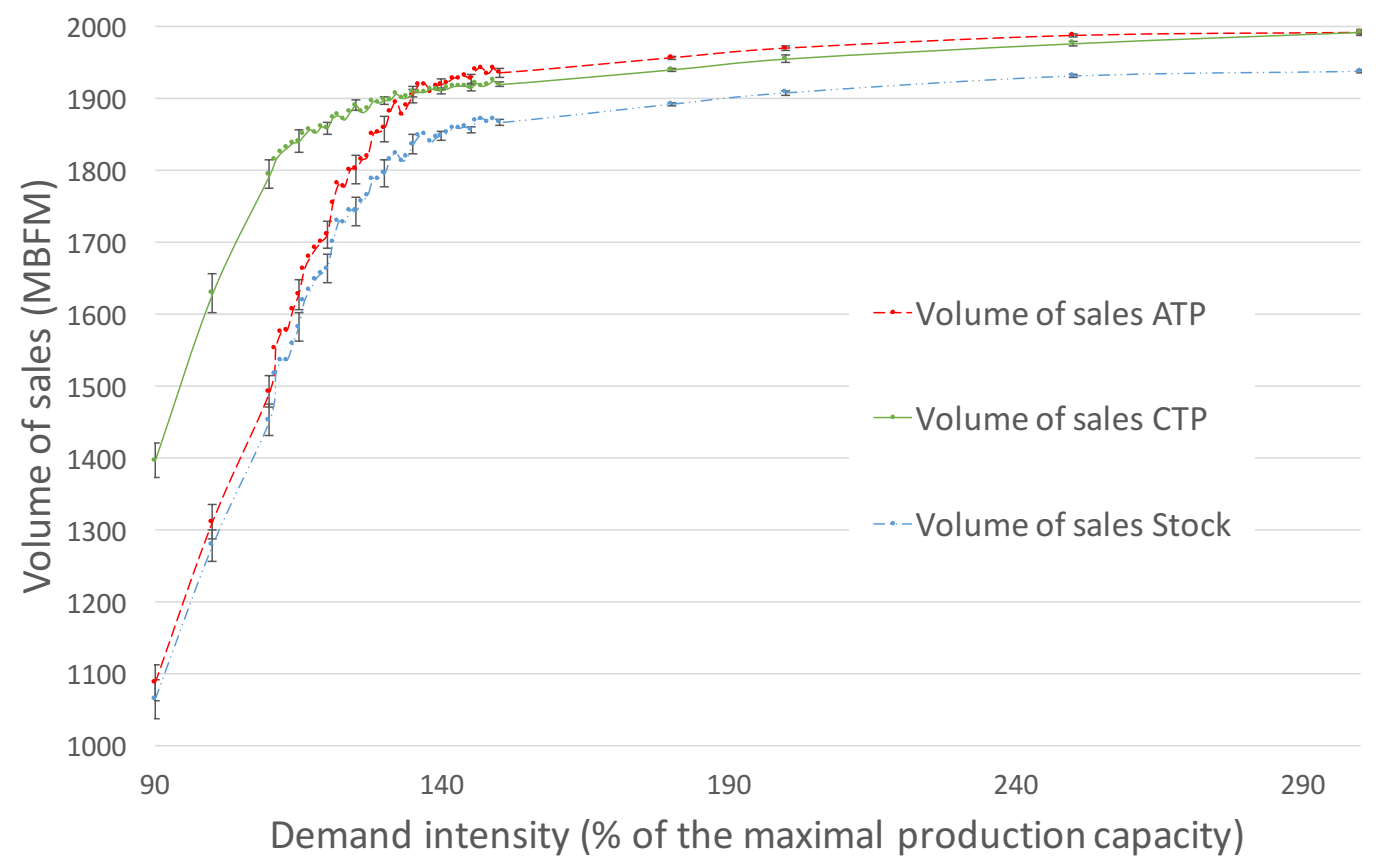

Figure 6: Volume of sales according to the demand intensity (Commodity product $=$ $70 \%$; accurate forecast; length of the planning horizon $=4$ weeks; replanning frequency $=1$ week)

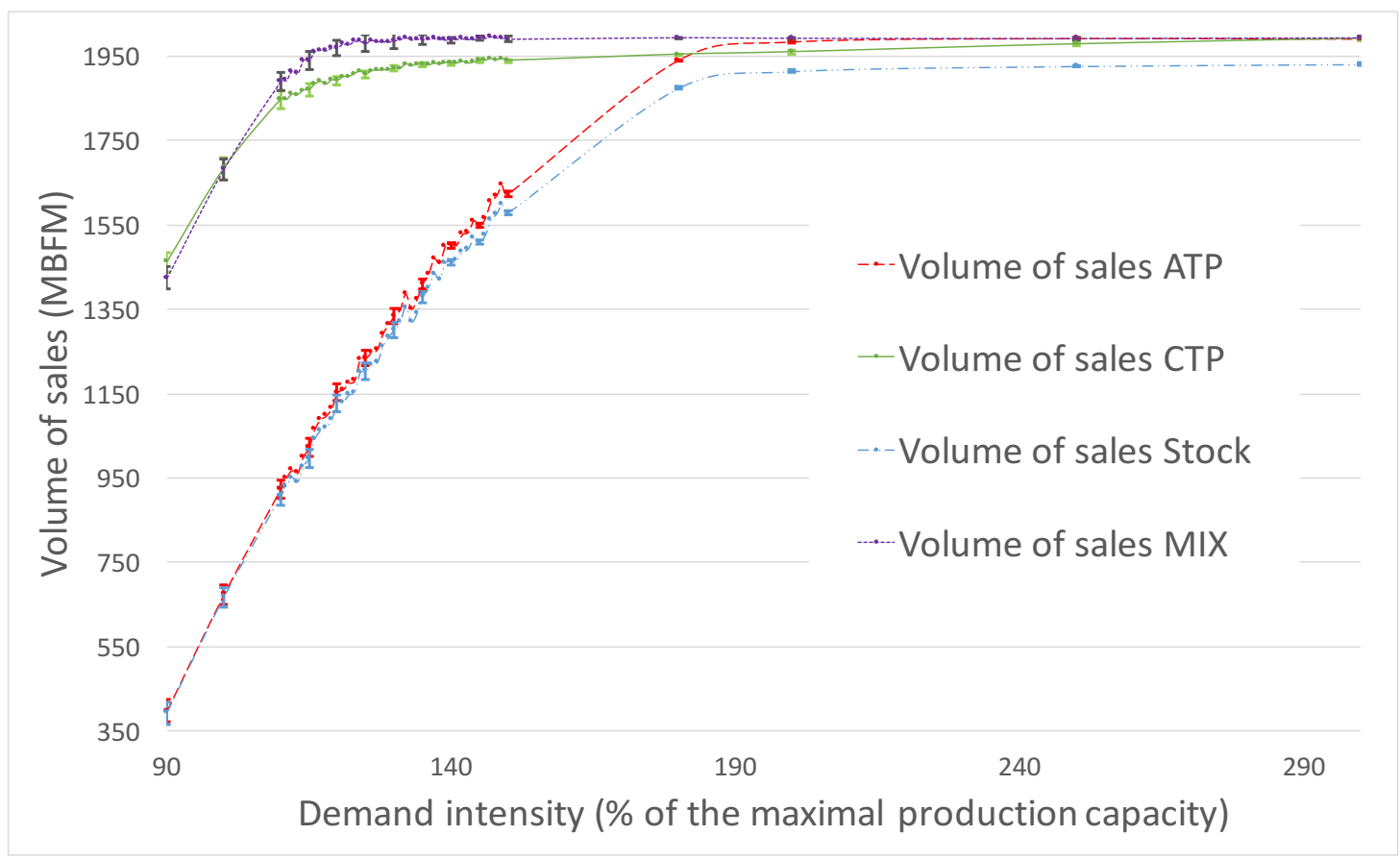


Figure 7: Average inventory over the year according to the demand intensity and the associated volume of sales (Commodity product $=90 \%$; accurate forecast; length of the planning horizon $=4$ weeks; replanning frequency $=1$ week)

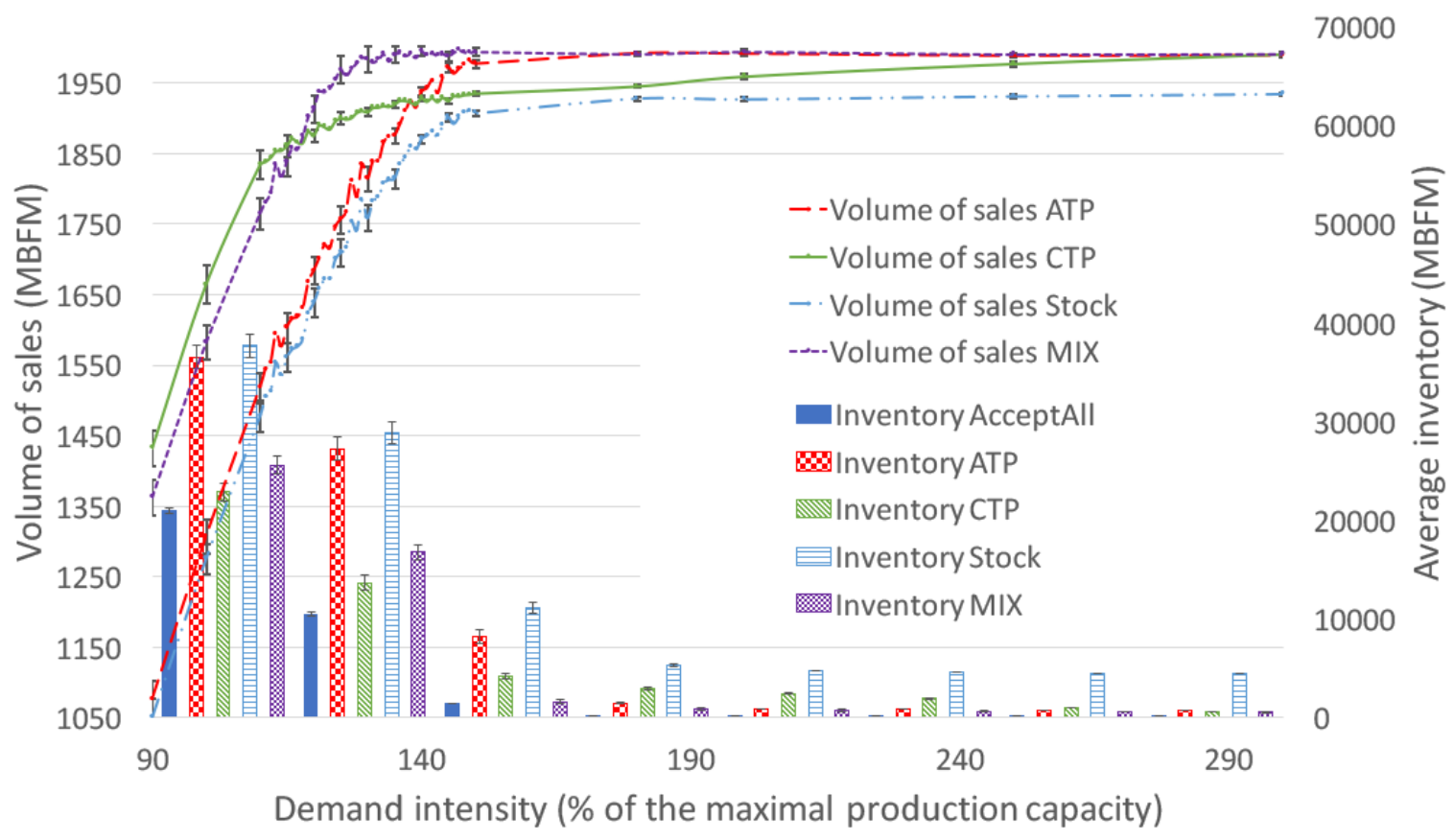

Figure 8: Revenues for each policy (commodity product $=70 \%$, accurate forecasts; length of the planning horizon $=4$ weeks; replanning frequency $=1$ week)

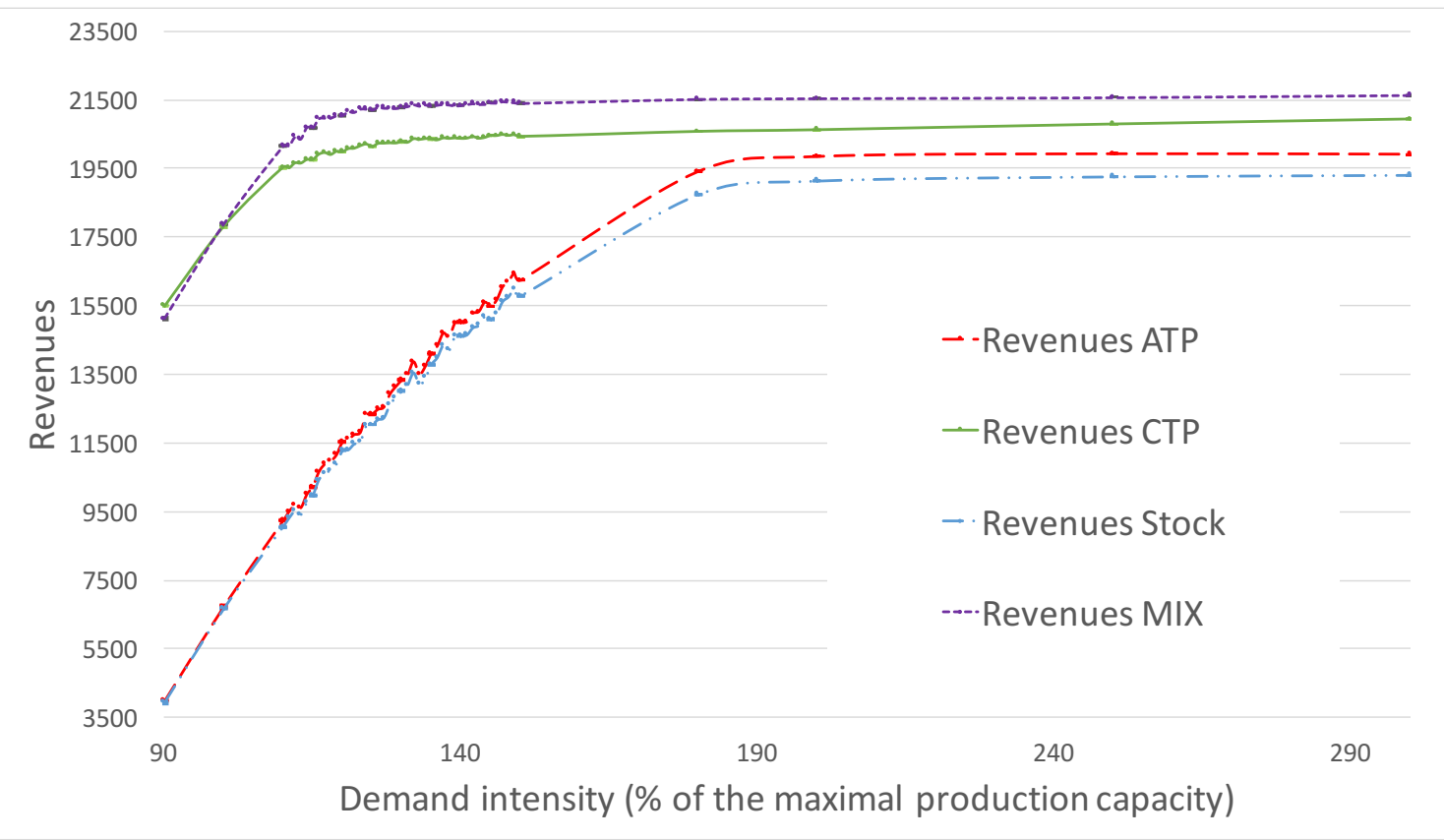


Figure 9: Decision graph taking into account the margin for a market with an accurate forecast (length of the planning horizon $=4$ weeks; replanning frequency $=1$ week)

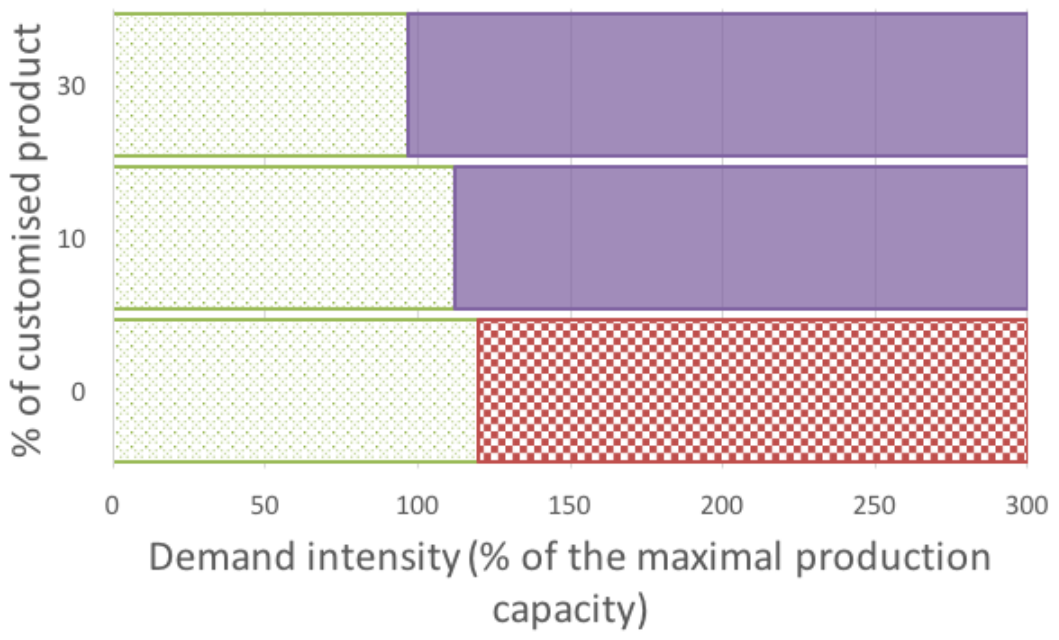

$\square$ CTP $⿴$ ATP $\square$ MIX 